\title{
Article \\ Descriptive Epidemiology of Rescue-Related Fatal Drowning in Turkey
}

\author{
Ali Işın ${ }^{1}$, Adnan Turgut ${ }^{2}$ and Amy E. Peden ${ }^{3, *}$ (D) \\ 1 Department of Coaching Education, Faculty of Sports Sciences, Akdeniz University, Antalya 07070, Turkey; \\ isin_ali@hotmail.com \\ 2 Department of Physical Education and Sports, Faculty of Sports Sciences, Akdeniz University, \\ Antalya 07070, Turkey; turgut@akdeniz.edu.tr \\ 3 School of Population Health, Faculty of Medicine, University of New South Wales, \\ Sydney, NSW 2052, Australia \\ * Correspondence: a.peden@unsw.edu.au
}

Citation: Işın, A.; Turgut, A.; Peden, A.E. Descriptive Epidemiology of Rescue-Related Fatal Drowning in Turkey. Int. J. Environ. Res. Public Health 2021, 18, 6613. https:// doi.org/10.3390/ijerph18126613

Academic Editor: Paul B. Tchounwou

Received: 23 May 2021

Accepted: 16 June 2021

Published: 19 June 2021

Publisher's Note: MDPI stays neutral with regard to jurisdictional claims in published maps and institutional affiliations.

Copyright: (c) 2021 by the authors. Licensee MDPI, Basel, Switzerland. This article is an open access article distributed under the terms and conditions of the Creative Commons Attribution (CC BY) license (https:// creativecommons.org/licenses/by/ $4.0 /)$.

\begin{abstract}
Drowning is a public-health threat and a leading cause of injury-related death. In Turkey, drowning results in 900 fatalities annually, and the rate is rising. As data on rescue-related drowning are scarce, this retrospective study explores the epidemiology of fatal drowning among rescuers in Turkey. As there are no routinely collected death registry data on drowning in Turkey, data were sourced from media reports of incidents between 2015 and 2019. Rescuer fatalities were analysed by age, sex, activity prior to rescue, location, incident day of week and season, and place of death. Statistical analyses comprised $X^{2}$ tests of significance $(p<0.05)$ and calculation of relative risk (95\% confidence interval) using fatality rates. In total, 237 bystander rescuers drowned (90\% male; $35 \%$ 15-24 years). In 33\% of cases, the primary drowning victim (PDV) was successfully rescued, while in $46 \%$ of cases the rescue resulted in multiple drowning fatalities (mean $=2.29$; range $1-5$ rescuers). Rescues were more likely to be successful in saving the PDV if undertaken at the beach/sea $\left(X^{2}=29.147 ; p<0.001\right)$, while swimming $\left(X^{2}=12.504 ; p=0.001\right)$, or during summer $\left(X^{2}=8.223\right.$; $p=0.029)$. Risk of bystander rescue-related fatal drowning was twice as high on weekdays compared to on weekends $(\mathrm{RR}=2.04 ; 95 \% \mathrm{CI}$ : $1.56-2.67)$. While bystanders play an important role in reducing drowning, undertaking a rescue is not without risk and can lead to multiple drowning incidents. Training in rescue and resuscitation skills (especially the prioritization of non-contact rescues) coupled with increasing awareness of drowning risk, are risk-reduction strategies which should be explored in Turkey.
\end{abstract}

Keywords: drowning; rescue; multiple drowning incident; prevention; injury; risk; epidemiology

\section{Introduction}

Drowning is a globally neglected threat to public health, resulting in 295,000 deaths worldwide each year [1]. However, this estimate excludes transportation and disasterrelated drowning fatalities [2], meaning the true burden is likely to be significantly higher. In Turkey, the unintentional fatal drowning rate is increasing; it rose from 0.89 per 100,000 population [3] between 2005 and 2011 to a current rate of 1.16 per 100,000 population [4].

Drowning is defined as a process, with outcomes ranging from death to survival with no ongoing injury [5]. Often those who experience non-fatal drowning are rescued at some stage during the drowning process, either by trained or volunteer lifesavers and lifeguards, or bystanders [6-8]. Surfers have also emerged as a group performing rescues in coastal environments [9]. Performing a rescue is not without risk and a small body of literature has emerged exploring the rescuer who drowns (the aquatic victim instead of rescuer [AVIR]) phenomena [8,10-12]. Such cases are often altruistic in nature, with rescues typically involving a child or loved one [10]. However, there is often a mismatch between willingness to perform an aquatic rescue and the skills needed to do so, particularly in 
open water, where most drowning incidents occur [13]. This indicates the need to provide training to potential bystander rescuers on rescue safety, something many report as never having been taught [14].

Drowning incidents which result in multiple fatalities (i.e., where both the rescuer and rescue drown), are a significant issue [11], contributing to the rising fatal drowning rate in Turkey [4]. As such, this present study aimed to investigate cases of the fatal drowning of bystander rescuers in Turkey between 2015-2019. In addition to identifying a range of risk factors, this study also explored multiple fatality events which occur during fatal bystander rescues to inform prevention efforts and curb Turkey's rising drowning toll.

\section{Materials and Methods}

This study takes a public health approach [15] to the issue of bystander rescue-related fatal unintentional drowning in Turkey. We do this through the collation of data to define the issue and conducting analysis to identify risk factors, both of which are used to provide evidence-informed recommendations for reducing such drowning incidents in Turkey.

\subsection{Study Design}

This retrospective study was undertaken exploring the fatal drowning of bystander rescuers which occurred in Turkey between 1 January 2015, and 31 December 2019. Bystander rescuers were defined as those who rescued someone from drowning while not acting in an official capacity (i.e., those who drowned while conducting a rescue while working as lifesavers or lifeguards were not included in this study). All multiple drowning incidents investigated in this study include bystander rescuers (i.e., incidents where more than one rescuer drowned). Thus, any drowning cases consisting of more than one victim without the drowning fatality of a bystander rescuer were not included in this study.

\subsection{Data Collection and Coding}

There are a lack of official statistics on drowning in Turkey [11]. Currently, the Turkish Statistical Institute (TurkStat) publishes annual data on causes of death (including external causes of injury and poisoning); however, such data are limited in their disaggregation and do not contain deaths by injury mechanism (such as drowning) [16]. In lieu of official data, fatal drowning incidents are collated using media reports $[3,4,17]$. This method has been used in many other countries in lieu of, or to supplement, official drowning statistics [18-21].

All unintentional drowning-related data were collected from online media reports via Google News [22]. Daily searches were run using regular and advanced search functions limiting region to Turkey and language to Turkish. A daily Google News digest email was also received to collate relevant cases. Search terms used were "boğulma" (drowning), "ölümcül boğulma" (fatal drowning), "kurtarma girişimi sırasında boğulma" (drowned during rescue attempt), and "kurtarıldı ve boğuldu" (rescued and drowned). Only news items published between 1 January 2015, and 31 December 2019 about incidents during the same period were included for analyses. Only unintentional fatal drowning events associated with rescues were evaluated. If a case was reported by more than one news source, these cases were evaluated as a single case. Where data reported were inconsistent, the name of the victim was searched across multiple reports and data confirmed.

The following data were extracted for each case and used in analyses: age, gender, activity prior to drowning, location of drowning incident, season of drowning incident, place of death and day of the week. The success of the bystander rescuer in successful rescuing the primary drowning victim was assessed and in cases of multiple drowning incidents, the number of fatalities were recorded.

The seasons of drowning incidents were classified as follows: Winter: December to February; Spring: March to May; Summer: June to August; Autumn: September to November. Place of death was coded into 'at the scene' or 'hospital'. The days of the week were coded into two groups as weekdays (Monday-Friday) and weekends (Saturday and 
Sunday). The activity being undertaken by the rescuer immediately prior to performing the rescue was coded as swimming, non-water related recreation, having a picnic, occupational (i.e., farmer, technician, self-employed, etc.) recreational fishing, boating and other. The place where the drowning occurred were coded as stream/river/creek, beach/sea, dam, lake/pond, irrigation channel, pool, and water hole. The two cases involving riverine floods were coded to stream/river/creek. Age groups were coded as 0-4 years, 5-14 years, 15-24 years, $25-34$ years, 35-44 years, $45-54$ years, 55 years and older.

\subsection{Data Analysis}

Descriptive data of the rescuers who drowned while attempting a rescue were presented as frequency (f) and percentage (\%). Chi square tests of significance were calculated using a Fisher's Exact Test $(p<0.05)$. Population data were retrieved from the Turkish Statistical Institute to calculate the mortality rate (per 100,000 population) [23]. Relative risk (RR) with a $95 \%$ confidence interval $(95 \% \mathrm{CI})$ was calculated for gender, age group, day of the week and seasons. In the calculation of RR and CI, the group with the lowest number of cases were used as the reference [4].

\subsection{Ethics Approval}

This study received ethics approval from the University of New South Wales Human Research Ethics Committee (HC210244).

\section{Results}

Across the study period, 237 bystander rescuers drowned. Annual mortality rates varied from a low of 0.04/100,000 people in 2017 to a high of 0.08 in 2019 (Figure 1). Males accounted for $89.9 \%$ of all bystander rescue-related drowning fatalities. The age group most commonly represent among bystander rescuer drowning fatalities was the 15-24 years age group $(35.0 \%)$. This was followed by the $25-34$ years age group $(20.7 \%)$ and the $5-14$ years age group $(14.3 \%)$ (Table 1$)$.

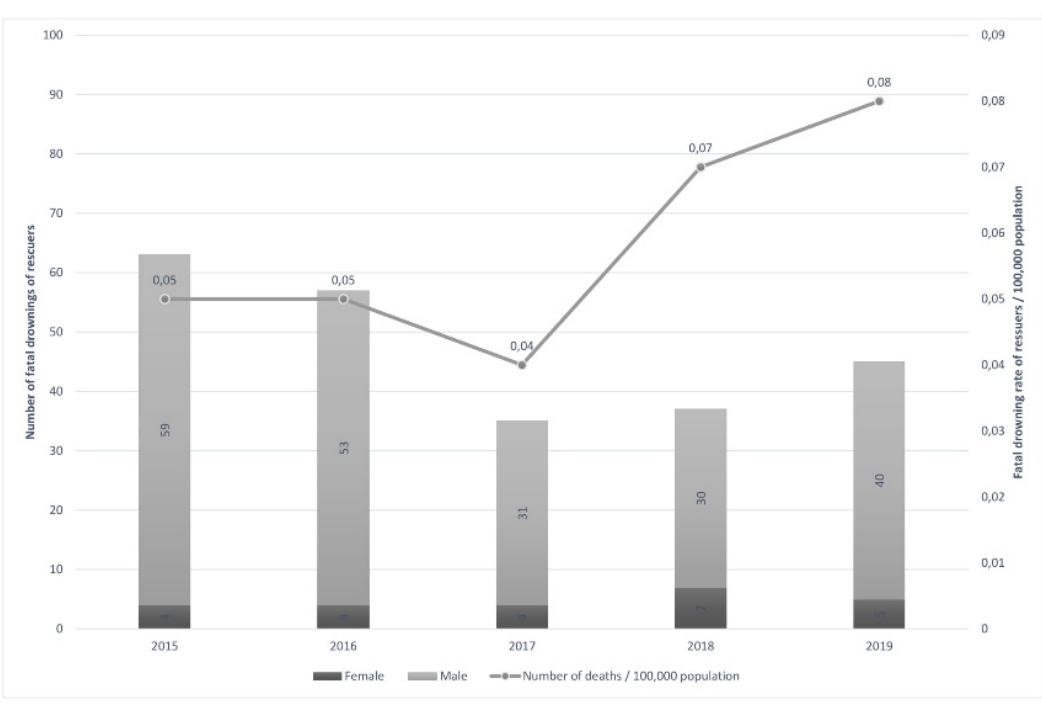

Figure 1. Frequency of unintentional bystander rescue-related fatal drowning and crude rate per 100,000 population by year of incident and sex; Turkey, 2015-2019. 
Table 1. Fatal drowning of bystander rescuers by status of rescue attempt, $X^{2}$ ( $p$ value); Turkey, 2015-2019.

\begin{tabular}{|c|c|c|c|c|c|c|c|}
\hline \multirow{2}{*}{ Factors } & \multicolumn{2}{|c|}{ Total } & \multicolumn{2}{|c|}{ Successful } & \multicolumn{2}{|c|}{ Unsuccessful } & \multirow[t]{2}{*}{$X^{2}(p$ Value $)$} \\
\hline & $\mathbf{N}$ & $\%$ & $\mathbf{N}$ & $\%$ & $\mathbf{N}$ & $\%$ & \\
\hline Total & 237 & 100.0 & 77 & 32.5 & 160 & 67.5 & - \\
\hline \multicolumn{8}{|l|}{ Sex } \\
\hline Male & 213 & 89.9 & 70 & 90.9 & 143 & 89.4 & \multirow{2}{*}{$0.134(p=0.821)$} \\
\hline Female & 24 & 10.1 & 7 & 9.1 & 17 & 10.6 & \\
\hline \multicolumn{8}{|l|}{ Age group (years) } \\
\hline $0-4$ & 1 & 0.4 & - & - & 1 & 0.6 & $0.483(p=1.000)$ \\
\hline $5-14$ & 34 & 14.3 & 7 & 9.1 & 27 & 16.9 & $2.563(p=0.118)$ \\
\hline $15-24$ & 83 & 35.0 & 29 & 37.7 & 54 & 33.8 & $0.350(p=0.564)$ \\
\hline $25-34$ & 49 & 20.7 & 16 & 20.8 & 33 & 20.6 & $0.001(p=1.000)$ \\
\hline $35-44$ & 33 & 13.9 & 12 & 15.6 & 21 & 13.1 & $0.262(p=0.689)$ \\
\hline $45-54$ & 22 & 9.3 & 10 & 13.0 & 12 & 7.5 & $1.859(p=0.231)$ \\
\hline $55+$ & 15 & 6.3 & 3 & 3.9 & 12 & 7.5 & $1.139(p=0.397)$ \\
\hline \multicolumn{8}{|l|}{ Day of week } \\
\hline Weekdays & 159 & 67.1 & 51 & 66.2 & 108 & 67.5 & \multirow{2}{*}{$0.038(p=0.883)$} \\
\hline Weekend & 78 & 32.9 & 26 & 33.8 & 52 & 32.5 & \\
\hline \multicolumn{8}{|l|}{ Place of death } \\
\hline At the scene & 213 & 89.9 & 66 & 85.7 & 147 & 91.9 & \multirow{2}{*}{$2.168(p=0.169)$} \\
\hline Hospital & 24 & 10.1 & 11 & 14.3 & 13 & 8.1 & \\
\hline \multicolumn{8}{|l|}{ Season } \\
\hline Summer & 151 & 63.7 & 59 & 76.6 & 92 & 57.5 & $8.223(p=0.004)$ \\
\hline Spring & 51 & 21.5 & 7 & 9.1 & 17 & 10.6 & $4.916(p=0.029)$ \\
\hline Autumn & 24 & 10.1 & 1 & 1.3 & 10 & 6.3 & $0.134(p=0.821)$ \\
\hline Winter & 11 & 4.6 & 10 & 13.0 & 41 & 25.6 & $2.879(p=0.109)$ \\
\hline \multicolumn{8}{|c|}{ Activity being undertaken prior to drowning } \\
\hline Swimming & 69 & 29.1 & 34 & 44.2 & 35 & 21.9 & $12.504(p=0.001)$ \\
\hline Non-water related recreation & 55 & 23.2 & 11 & 14.3 & 44 & 27.5 & $5.093(p=0.032)$ \\
\hline Having a picnic & 44 & 18.6 & 12 & 15.6 & 32 & 20.0 & $0.670(p=0.478)$ \\
\hline Occupational & 31 & 13.1 & 9 & 11.7 & 22 & 13.8 & $0.194(p=0.837)$ \\
\hline Recreational fishing & 22 & 9.3 & 3 & 3.9 & 19 & 11.9 & $3.930(p=0.056)$ \\
\hline Others & 16 & 6.8 & 8 & 10.4 & 8 & 5.0 & $0.729(p=0.392)$ \\
\hline \multicolumn{8}{|l|}{ Location of drowning incident } \\
\hline Stream/River/Creek & 81 & 34.1 & 20 & 26.0 & 61 & 38.2 & $3.412(p=0.079)$ \\
\hline Beach/Sea & 59 & 24.9 & 36 & 46.8 & 23 & 14.4 & $29.147(p<0.001)$ \\
\hline Dam & 30 & 12.7 & 6 & 7.8 & 24 & 15.0 & $2.443(p=0.146)$ \\
\hline Lake/Pond & 27 & 11.4 & 5 & 6.5 & 22 & 13.8 & $2.712(p=0.127)$ \\
\hline Irrigation channel & 26 & 11.0 & 8 & 10.4 & 18 & 11.3 & $0.039(p=1.000)$ \\
\hline Pool & 7 & 3.0 & 1 & 1.3 & 6 & 3.8 & $1.090(p=0.433)$ \\
\hline Water hole & 7 & 3.0 & 1 & 1.3 & 6 & 3.8 & $1.090(p=0.433)$ \\
\hline
\end{tabular}

Bold text indicates statistical significance.

Bystander rescue-related fatal drownings were more likely to occur on weekdays (67.1\%) (Table 1). A slightly higher proportion of female bystander rescue related fatal drownings occurred on weekends $(33.3 \%)$ as opposed to males $(32.9 \%)$, although this difference was not statistically significant (Table 2).

The vast majority of drowning fatalities occurred at the scene (89.9\%), with just $10.1 \%$ of bystander rescuers dying in hospital (Table 1). There were no statistically significant differences in place of death by sex of rescuer (Table 2). 
Table 2. Fatal drowning of bystander rescuers by sex, $X^{2}$ ( $p$ value), Turkey, 2015-2019.

\begin{tabular}{|c|c|c|c|c|c|c|c|}
\hline \multirow{2}{*}{ Factors } & \multicolumn{2}{|c|}{ Total } & \multicolumn{2}{|c|}{ Male } & \multirow{2}{*}{$\begin{array}{c}\text { Female } \\
\mathbf{N}\end{array}$} & \multirow[b]{2}{*}{$\%$} & \multirow[t]{2}{*}{$\mathrm{X}^{2}(p$ Value $)$} \\
\hline & $\mathbf{N}$ & $\%$ & $\mathbf{N}$ & $\%$ & & & \\
\hline Total & 237 & 100.0 & 213 & 89.9 & 24 & 10.1 & - \\
\hline \multicolumn{8}{|l|}{ Age group (years) } \\
\hline $0-4$ & 1 & 0.4 & 1 & 0.5 & - & - & $0.113(p=1.000)$ \\
\hline $5-14$ & 34 & 14.3 & 28 & 13.1 & 6 & 25.0 & $2.467(p=0.127)$ \\
\hline $15-24$ & 83 & 35.0 & 76 & 35.7 & 7 & 29.2 & $0.402(p=0.654)$ \\
\hline $25-34$ & 49 & 20.7 & 46 & 21.6 & 3 & 12.5 & $1.088(p=0.427)$ \\
\hline $35-44$ & 33 & 13.9 & 28 & 13.1 & 5 & 20.8 & $1.064(p=0.347)$ \\
\hline $45-54$ & 22 & 9.3 & 20 & 9.4 & 2 & 8.3 & $0.029(p=1.000)$ \\
\hline $55+$ & 15 & 6.3 & 14 & 6.6 & 1 & 4.2 & $0.211(p=1.000)$ \\
\hline \multicolumn{8}{|l|}{ Day of week } \\
\hline Weekdays & 159 & 67.1 & 143 & 67.1 & 16 & 66.7 & \multirow{2}{*}{$0.002(p=1.000)$} \\
\hline Weekend & 78 & 32.9 & 70 & 32.9 & 8 & 33.3 & \\
\hline \multicolumn{8}{|l|}{ Place of death } \\
\hline At the scene & 213 & 89.9 & 191 & 89.7 & 22 & 91.7 & \multirow{2}{*}{$0.094(p=1.000)$} \\
\hline In the hospital & 24 & 10.1 & 22 & 10.3 & 2 & 8.3 & \\
\hline \multicolumn{8}{|l|}{ Season } \\
\hline Summer & 151 & 63.7 & 136 & 63.8 & 15 & 62.5 & $0.017(p=1.000)$ \\
\hline Spring & 51 & 21.5 & 45 & 21.1 & 6 & 25.0 & $0.192(p=0.610)$ \\
\hline Autumn & 24 & 10.1 & 22 & 10.3 & 2 & 8.3 & $0.094(p=1.000)$ \\
\hline Winter & 11 & 4.6 & 10 & 4.7 & 1 & 4.2 & $0.014(p=1.000)$ \\
\hline \multicolumn{8}{|c|}{ Activity being undertaken prior to drowning } \\
\hline Swimming & 69 & 29.1 & 64 & 30.0 & 5 & 20.8 & $0.887(p=0.478)$ \\
\hline Non-water related recreation & 55 & 23.2 & 48 & 22.5 & 7 & 29.2 & $0.532(p=0.452)$ \\
\hline Having a picnic & 44 & 18.6 & 35 & 16.4 & 9 & 37.5 & $6.333(p=0.023)$ \\
\hline Occupational & 31 & 13.1 & 29 & 13.6 & 2 & 8.3 & $0.529(p=0.749)$ \\
\hline Recreational fishing & 22 & 9.3 & 22 & 10.3 & - & - & $2.733(p=0.141)$ \\
\hline Others & 16 & 6.8 & 15 & 7.0 & 1 & 4.2 & $0.146(p=1.000)$ \\
\hline \multicolumn{8}{|c|}{ Location of drowning incident } \\
\hline Stream/River/Creek & 81 & 34.1 & 74 & 34.7 & 7 & 29.2 & $0.298(p=0.656)$ \\
\hline Beach/Sea & 59 & 24.9 & 54 & 25.4 & 5 & 20.8 & $0.236(p=0.805)$ \\
\hline Dam & 30 & 12.7 & 24 & 11.3 & 6 & 25.0 & $3.679(p=0.096)$ \\
\hline Lake/Pond & 27 & 11.4 & 25 & 11.7 & 2 & 8.3 & $0.248(p=1.000)$ \\
\hline Irrigation channel & 26 & 11.0 & 25 & 11.7 & 1 & 4.2 & $1.266(p=0.488)$ \\
\hline Pool & 7 & 3.0 & 6 & 2.8 & 1 & 4.2 & $0.137(p=0.531)$ \\
\hline Water hole & 7 & 3.0 & 5 & 2.3 & 2 & 8.3 & $2.696(p=0.151)$ \\
\hline
\end{tabular}

Bold text indicates statistical significance.

Summer $(63.7 \%)$, followed by Spring $(21.5 \%)$ are the seasons with the highest proportions of bystander rescue-related drowning fatalities. A slightly higher proportion of females drowned in bystander-rescue-related incidents in Spring (25.0\%) compared to males $(21.1 \%)$; however, there was no statistically significant difference by sex of rescuer and season of incident (Table 2).

Swimming $(29.1 \%)$ was the leading activity in fatal drownings of bystander rescuers, followed by non-water related recreation $(23.2 \%)$ and having a picnic $(18.6 \%)$. When activity prior to bystander rescue-related drowning was explored by sex of the rescuer, females were significantly more likely to fatally drown while conducting a bystander rescue while having a picnic $\left(X^{2}=6.333 ; p=0.023\right)$. Stream $/$ River/Creek $(34.7 \%)$ was the leading location for bystander rescue-related drowning fatalities, followed by Beach/Sea $(24.9 \%)$ and Dam (12.7\%) (Table 1). There were no significant differences in bystander rescue drowning fatalities by sex and location of drowning incident (Table 2). 
When exploring rescue attempts by success of rescuing the person who was drowning, in 77 cases $(32.5 \%)$ the primary drowning victim was rescued. In $54.4 \%(n=129)$ of cases there was one bystander rescuer who drowned. In almost half of all cases $(45.5 \% ; n=108)$ the bystander rescue resulted in multiple rescuers drowning (mean $=2.29$; range $1-5$ rescuers) (Table 3$)$.

Table 3. Success of rescuers in rescuing and number of multiple drowning incidents.

\begin{tabular}{ccc}
\hline Success of Rescuers in Rescuing & $\mathbf{N}$ & $\mathbf{\%}$ \\
\hline Unsuccessful & 160 & 67.5 \\
Successful & 77 & 32.51 \\
\hline Number of rescuer drowning fatalities per incident & $\mathbf{N}$ & $\mathbf{\%}$ \\
\hline 1 & 129 & 54.4 \\
2 & 86 & 36.3 \\
3 & 15 & 6.3 \\
4 & 5 & 2.1 \\
5 & 2 & 0.8 \\
\hline
\end{tabular}

Rescues were significantly more likely to be successful in saving the primary drowning victim if they occurred at the beach or sea $\left(X^{2}=29.147 ; p<0.001\right)$, while swimming $\left(X^{2}=12.504 ; p=0.001\right)$, or during the summer months $\left(X^{2}=8.223 ; p=0.004\right)$. Bystander rescues were more likely to be unsuccessful in saving the primary drowning victim if they occurred during non-water related activities $\left(X^{2}=5.093 ; p<0.032\right)$ or during Spring $\left(\mathrm{X}^{2}=4.916 ; p<0.029\right)$ (Table 1$)$.

When compared to females, male bystander rescuers drowned during rescue attempts almost nine-times ( $\mathrm{RR}=8.81 ; 95 \% \mathrm{CI}$ : 5.78-13.44) more frequently. Risk of fatally drowning while undertaking a bystander rescue was highest among those 15-24 years old, 82-times higher than the risk for 0-4-year-old individuals ( $\mathrm{RR}=82.21 ; 95 \% \mathrm{CI}$ : 11.44-253.04). The risk of death on weekdays was twice as high $(\mathrm{RR}=2.04 ; 95 \% \mathrm{CI}$ : 1.56-2.67) compared to the weekend. Compared to winter, the highest risk of drowning was in the summer $(\mathrm{RR}=13.73$; 95\%CI: 7.45-25.30), followed by spring $(\mathrm{RR}=4.64 ; 95 \% \mathrm{CI}: 2.42-8.90)$ and autumn (RR $=2.18 ; 95 \% \mathrm{CI}$ : 1.07-4.45) (Table 4$)$.

Table 4. Relative risk (95\% confidence interval) by gender, age group, day of the week and season of drowning incident.

\begin{tabular}{|c|c|c|c|}
\hline Factors & Number of Deaths & Drowning Rate & $\begin{array}{c}\text { Relative Risk } \\
\text { (95\% Confidence Interval) }\end{array}$ \\
\hline \multicolumn{4}{|l|}{ Gender } \\
\hline Female & 24 & 0.06 & 1 \\
\hline Male & 213 & 0.52 & $8.81(5.78-13.44)$ \\
\hline \multicolumn{4}{|l|}{ Age groups } \\
\hline $0-4$ years & 1 & 0.02 & 1 \\
\hline 5-14 years & 34 & 0.54 & $34.64(4.74-253.04)$ \\
\hline $15-24$ years & 83 & 1.28 & $82.21(11.44-590.56)$ \\
\hline 25-34 years & 49 & 0.78 & $49.80(6.88-360.68)$ \\
\hline 35-44 years & 33 & 0.54 & $34.76(4.76-254.14)$ \\
\hline $45-54$ years & 22 & 0.46 & $29.20(3.94-216.70)$ \\
\hline $55+$ years & 15 & 0.31 & $20.09(2.65-152.10)$ \\
\hline \multicolumn{4}{|l|}{ Day of week } \\
\hline Weekend & 78 & 0.10 & 1 \\
\hline Weekday & 159 & 0.20 & $2.04(1.56-2.67)$ \\
\hline \multicolumn{4}{|l|}{ Season } \\
\hline Winter & 11 & 0.01 & 1 \\
\hline Autumn & 24 & 0.03 & $2.18(1.07-4.45)$ \\
\hline Spring & 51 & 0.06 & $4.64(2.42-8.90)$ \\
\hline Summer & 151 & 0.19 & $13.73(7.45-25.30)$ \\
\hline
\end{tabular}




\section{Discussion}

Drowning is a leading cause of preventable death globally and in Turkey [1]. Although many measures have been recommended to prevent such deaths [24], drowning fatalities in Turkey are increasing [4]. While bystander rescuers play an important role in preventing drowning, especially in unpatrolled locations or in countries without lifeguarding or lifesaving services, this is not without risk [8,10-12]. This study reports the demographics and risk factors associated with fatal drowning of bystanders during rescues in Turkey and found that bystander rescue-related drowning fatalities have doubled since 2017, contributing to the rising fatal drowning toll in Turkey [4].

In the present study, male rescuers were eight-times more likely to drown while performing a bystander rescue than females. Similarly, the overrepresentation of males in rescue-related drowning has previously been identified $[8,11,20]$. Gender is among one of the most important risk factors for drowning, and it is known that males have a higher risk of drowning than females [17,25-27]. When the underlying reasons are examined, it has been reported that males are exposed to water more than females, and they participate in water-based recreational activities more frequently, spend longer in deeper water and are more likely to enter the water under the influence of alcohol or refuse to wear a lifejacket [4,28-32]. Increased exposure coupled with a risk-taking mentality may contribute to increased drowning risk among males when performing bystander rescues. While all people should be trained in safe rescue and resuscitation skills to improve outcomes and reduce risk [10], this can be extremely challenging in resource-poor environments. Turkish data indicate that males should be prioritized for such training, particularly those 15-34 years of age. Population-level coverage of rescue and resuscitation skills may be best achieved through school and workplace training programs. Training may also contribute to a reduction in incidents involving multiple fatalities of rescuers.

Of concern, $14 \%$ of all drowning fatalities of bystander rescuers in this study were of children and adolescents 5-14 years of age. Preventing drowning among this age group is challenging. While adult supervision is key for younger children, towards the upper end of this age group, adolescents may begin to recreate around water with peers, rather than parents or caregivers. It is, therefore, vital that this age group are taught non-contact rescue skills such as a 'talk', 'throw' or 'reach' rescue [33]. However, 'throw' and 'reach' rescues rely on access to safety equipment or tools that can be used in such rescues, which are often not available or are limited in Turkey, particularly at natural waterways [11].

In this study, natural fresh waters, such as streams, rivers and creeks were the most common location for fatal drownings of bystander rescuers. Rivers have been identified as a leading location for drowning, where prevention is often challenging due to changeable conditions and geographical isolation [34]. Swimming in rivers is often more risky than the beach or ocean, due to a lack of lifeguards and designated safe swimming areas [4]. While beach/sea was the second most common place for bystander rescue-related fatal drownings in this study, rescuers were significantly more likely to have been successful in rescuing the primary drowning victim at such locations. The specific circumstances of why this might be, such as the presence of others to assist, higher familiarity with conditions, and proximity to medical care, warrants further investigation.

In the current study, $33 \%$ of rescuers who died by drowning were successful in rescuing the primary drowning victim. This is an increase from $27 \%$ in a previous study conducted in Turkey between 2005 and 2008 [11]. However, such rates are significantly lower than the proportion of successful rescue attempts by bystanders reported in Australia [10]. This may be due to a stronger culture of swimming and lifesaving training, greater training in cardio-pulmonary resuscitation and the presence of public rescue equipment in Australia. However, in Turkey, attempts to rescue people who are drowning are often unsuccessful, and result in the deaths of both the primary drowning victim and the rescuer. Training in rescue and resuscitation, the installation of public rescue equipment at prominent drowning locations and enhanced public education are strategies that could be implemented and evaluated in Turkey to reduce the preventable loss of life in bystander rescue incidents. 
Similarly, resuscitation skills are likely to be a significant tertiary prevention skill, given that this study has identified that the vast majority $(90 \%)$ of bystander rescuers died at the scene, rather than in the hospital. This indicates the need for rapid and effective on-site medical care [35].

With the development of technology, drones have started to be used in many areas, including for the prevention of drowning [36]. Using drones may offer the opportunity to reach submerged people earlier than traditional search strategies. The delivery of flotation devices to drowning victims with the help of drones may be an effective solution, especially in isolated locations or where the victim cannot be reached through traditional non-contact rescue methods [37]. However, this strategy relies on the victim being conscious and able to reach and use the floatation device.

This study utilized data collected from online media reports, due to a lack of data on drowning in Turkey. While media reports have been used to collate drowning data previously, both in Turkey [3,4,17] and elsewhere [18-21], the reliance on such data sources, highlights the need to strengthen drowning data surveillance systems in Turkey, a strategy recommended by the World Health Organization [24]. This includes disaggregation of external cause-code fatality data by injury mechanism [16]. Furthermore, investment in prevention would be well served by the establishment of a detailed drowning registry which nationally captures both fatal and non-fatal drowning incidents, to better identify at-risk groups and inform population-, location-and activity-based prevention efforts. The media-based reporting of drowning may be one strategy to collate data on drowning as it is in countries such as Australia [21], while also presenting an important opportunity for highlighting rescue safety when reporting such tragic incidents.

\section{Strengths and Limitations}

The data presented in this study provide the prevalence of fatal drowning among bystander rescuers in Turkey. This is the most comprehensive study of rescuer drowning ever conducted in Turkey, with analyses identifying at risk groups, locations and activities on which to focus prevention efforts. However, there are several limitations associated with this study. As reported many times, there is a notable lack of data related to drowning in Turkey; therefore, media reports are used to identify cases of fatal drowning. While media reports have been found to have complete capture of bystander rescue-related drowning in Australia [21], this may not be the case in Turkey. Similarly, the variables reported in this study may not have been accurately reported by the media. Data on the race/ethnicity of those who drowned is not currently collected, nor is it well-reported within the media. It is, however, an important topic that is likely to impact drowning risk and, therefore, it is recommended that these data be collected, in so far as it is possible, in the future. This study did not capture a number of primary drowning victims. Fatal drowning rates are calculated per 100,000 population and, therefore, do not take into account exposure.

\section{Conclusions}

This study focused on the risk factors related to fatal drowning of bystanders during rescues in Turkey. Our study provides evidence that bystander rescuers are notably increasing with the number of drownings in Turkey. In the vast majority of fatal rescue attempts, bystander rescuers also failed to rescue the primary drowning victim. The results show that untrained bystander rescue attempts are not without risk and, thus, bystanders should be trained in non-contact recovery techniques. Consideration should also be given to population level education and to the exploration of emerging technologies.

Author Contributions: Conceptualization, A.I., A.T. and A.E.P.; methodology, A.I. and A.E.P.; formal analysis, A.I. and A.E.P.; investigation, A.I., A.T. and A.E.P.; resources, A.I., A.T. and A.E.P.; data curation, A.I. and A.T.; writing—original draft preparation, A.I. and A.E.P.; writing-review and editing, A.I., A.T. and A.E.P.; visualization, A.I., A.T. and A.E.P.; supervision, A.T. and A.E.P.; project administration, A.I., A.T. and A.E.P. All authors have read and agreed to the published version of the manuscript. 
Funding: This research received no external funding.

Institutional Review Board Statement: The study was conducted according to the guidelines of the Declaration of Helsinki and approved by the University of New South Wales Human Research Ethics Committee (HC210244).

Informed Consent Statement: Informed consent was not obtained as this study involves data on fatal drowning reported in the media.

Data Availability Statement: Data may be made available upon reasonable request. Please contact data custodian Ali Işın (isin_ali@hotmail.com) for further information.

Conflicts of Interest: The authors declare no conflict of interest.

\section{References}

1. Franklin, R.C.; Peden, A.E.; Hamilton, E.B.; Bisignano, C.; Castle, C.D.; Dingels, Z.V.; Hay, S.I.; Liu, Z.; Mokdad, A.H.; Roberts, N.L.; et al. The burden of unintentional drowning: Global, regional and national estimates of mortality from the Global Burden of Disease 2017 Study. Inj. Prev. 2020. [CrossRef]

2. Peden, A.E.; Franklin, R.C.; Mahony, A.J.; Scarr, J.; Barnsley, P.D. Using a retrospective cross-sectional study to analyse unintentional fatal drowning in Australia: ICD-10 coding-based methodologies verses actual deaths. BMJ Open 2017, 7. [CrossRef]

3. Turgut, A.; Turgut, T. A population-based study on deaths by drowning incidents in Turkey. Int. J. Inj. Contr. Saf. Promot. 2014, 21, 61-67. [CrossRef] [PubMed]

4. Işın, A.; Akdă̆, E.; Turgut, A. The epidemiology of fatal drowning in children: A 13-year retrospective study in Turkey. Int. J. Inj. Control Saf. Promot. 2020, 27, 465-471. [CrossRef]

5. $\quad$ van Beeck, E.F.; Branche, C.M.; Szpilman, D.; Modell, J.H.; Bierens, J.J. A new definition of drowning: Towards documentation and prevention of a global public health problem. Bull. World Health Organ. 2005, 83, 853-856.

6. Brander, R.W.; Warton, N.; Franklin, R.C.; Shaw, W.S.; Rijksen, E.J.; Daw, S. Characteristics of aquatic rescues undertaken by bystanders in Australia. PLoS ONE 2019, 14, e0212349. [CrossRef]

7. Ma, W.; Xu, Y.; Xu, X. Is drowning a serious public health problem in Guangdong Province, People's Republic of China?-Results from a retrospective population-based survey, 2004-2005. Int. J. Inj. Control Saf. Promot. 2010, 17, 103-110. [CrossRef]

8. Franklin, R.C.; Peden, A.E.; Brander, R.W.; Leggat, P.A. Who rescues who? Understanding aquatic rescues in Australia using coronial data and a survey. Aust. N. Z. J. Public Health 2019, 43, 477-483. [CrossRef] [PubMed]

9. Attard, A.; Brander, R.W.; Shaw, W.S. Rescues conducted by surfers on Australian beaches. Accid. Anal. Prev. 2015, 82, 70-78. [CrossRef]

10. Franklin, R.C.; Pearn, J.H. Drowning for love: The aquatic victim-instead-of-rescuer syndrome: Drowning fatalities involving those attempting to rescue a child. J. Paediatr. Child Health 2011, 47, 44-47. [CrossRef] [PubMed]

11. Turgut, A.; Turgut, T. A study on rescuer drowning and multiple drowning incidents. J. Saf. Res. 2012, 43, 129-132. [CrossRef]

12. Lawes, J.C.; Rijksen, E.J.; Brander, R.W.; Franklin, R.C.; Daw, S. Dying to help: Fatal bystander rescues in Australian coastal environments. PLoS ONE 2020, 15, e0238317. [CrossRef]

13. Moran, K.; Stanley, T. Readiness to rescue: Bystander perceptions of their capacity to respond in a drowning emergency. Int. J. Aquat. Res. Educ. 2013, 7, 3. [CrossRef]

14. Moran, K.; Webber, J.; Stanley, T. The 4Rs of aquatic rescue: Educating the public about safety and risks of bystander rescue. Int. J. Inj. Control Saf. Promot. 2017, 24, 396-405. [CrossRef]

15. Violence Prevention Alliance. The Public Health Approach. Available online: https://www.who.int/violenceprevention/ approach/public_health/en/ (accessed on 22 February 2019).

16. Institute, T.S. Data Portal for Statistics-Health and Social Protection. Available online: https://data.tuik.gov.tr/Kategori/ GetKategori?p=Health-and-Social-Protection--101 (accessed on 7 April 2021).

17. Turgut, A.; Işın, A.; Akdağ, E. Yüzme Havuzlarındaki Suda Boğulma Vakalarının İncelenmesi. İstanbul Üniversitesi Spor Bilimleri Derg. 2018, 8, 69-76.

18. Barss, P.; Subait, O.M.; Al Ali, M.H.; Grivna, M. Drowning in a high-income developing country in the Middle East: Newspapers as an essential resource for injury surveillance. J. Sci. Med. Sport 2009, 12, 164-170. [CrossRef] [PubMed]

19. Lunetta, P.; Tiirikainen, K.; Smith, G.S.; Penttilä, A.; Sajantila, A. How well does a national newspaper reporting system profile drowning? Int. J. Inj. Contr. Saf. Promot. 2006, 13, 35-41. [CrossRef] [PubMed]

20. Zhu, Y.; Jiang, X.; Li, H.; Li, F.; Chen, J. Mortality among drowning rescuers in China, 2013: A review of 225 rescue incidents from the press. BMC Public Health 2015, 15, 1-8. [CrossRef]

21. Peden, A.E.; Franklin, R.C.; Willcox-Pidgeon, S. Media reporting of summer drowning: A partial picture, useful for advocacy. Health Promot. J. Aust. 2020, 31, 491-496. [CrossRef]

22. Google. Google News. Available online: www.news.google.com (accessed on 12 April 2021).

23. Institute, T.S. Population and Demography. Available online: https://data.tuik.gov.tr/Kategori/GetKategori?p=nufus-vedemografi-109\&dil=1 (accessed on 17 February 2021). 
24. World Health Organization. Preventing Drowning: An Implementation Guide; World Health Organization: Geneva, Switzerland, 2017.

25. Peden, A.E.; Franklin, R.C.; Clemens, T. Exploring the burden of fatal drowning and data characteristics in three high income countries: Australia, Canada and New Zealand. BMC Public Health 2019, 19, 794. [CrossRef]

26. Howland, J.; Hingson, R.; Mangione, T.; Bell, N.; Bak, S. Why are most drowning victims men? Sex differences in Aquatic Skills and Behaviors. Am. J. Public Health 1996, 86, 93-96. [CrossRef] [PubMed]

27. Croft, J.L.; Button, C. Interacting factors associated with adult male drowning in New Zealand. PLoS ONE 2015, 10, e0130545. [CrossRef]

28. Peden, A.E.; Franklin, R.C.; Leggat, P.A. Breathalysing and surveying river users in Australia to understand alcohol consumption and attitudes toward drowning risk. BMC Public Health 2018, 18, 1393. [CrossRef] [PubMed]

29. Peden, A.E.; Franklin, R.C.; Leggat, P.A. Exploring visitation at rivers to understand drowning risk. Inj. Prev. 2019, 25, 392-399. [CrossRef]

30. Morgan, D.; Ozanne-Smith, J.; Triggs, T. Self-reported water and drowning risk exposure at surf beaches. Aust. N. Z. J. Public Health 2009, 33, 180-188. [CrossRef]

31. Morgan, D.; Ozanne-Smith, J.; Triggs, T. Direct observation measurement of drowning risk exposure for surf beach bathers. J. Sci. Med. Sport 2009, 12, 457-462. [CrossRef]

32. Peden, A.E.; Demant, D.; Hagger, M.S.; Hamilton, K. Personal, social, and environmental factors associated with lifejacket wear in adults and children: A systematic literature review. PLoS ONE 2018, 13, e0196421. [CrossRef]

33. Pearn, J.H.; Franklin, R.C. "Flinging the squaler" lifeline rescues for drowning prevention. Int. J. Aquat. Res. Educ. 2009, 3, 9. [CrossRef]

34. Peden, A.; Franklin, R.C.; Leggat, P.A. Fatal River Drowning: Identification of Research Gaps through a Systematic Literature Review. Inj. Prev. 2016, 22, 202-209. [CrossRef]

35. Venema, A.M.; Groothoff, J.W.; Bierens, J.J. The role of bystanders during rescue and resuscitation of drowning victims. Resuscitation 2010, 81, 434-439. [CrossRef]

36. Claesson, A.; Svensson, L.; Nordberg, P.; Ringh, M.; Rosenqvist, M.; Djarv, T.; Samuelsson, J.; Hernborg, O.; Dahlbom, P.; Jansson, A. Drones may be used to save lives in out of hospital cardiac arrest due to drowning. Resuscitation 2017, 114, 152-156. [CrossRef] [PubMed]

37. Bäckman, A.; Hollenberg, J.; Svensson, L.; Ringh, M.; Nordberg, P.; Djärv, T.; Forsberg, S.; Hernborg, O.; Claesson, A. Drones for provision of flotation support in simulated drowning. Air Med. J. 2018, 37, 170-173. [CrossRef] 